INTEGRATIVE LITERATURE REVIEWS AND META-ANALYSES

\title{
The process of hospital discharge for medical patients: a model
}

Pauline Pearson BA PhD RN RHV

2 Department of Primary Health Care, University of Newcastle upon Tyne, Newcastle upon Tyne, UK

Susan Procter BSc PhD CertEd RGN

St Bartholomew's School of Nursing and Midwifery, City University, London, UK

Jane Wilcockson BA PhD

Nursing, Midwifery and Allied Health Professions Research Unit, Northumbria University, Newcastle upon Tyne, UK

Vicki Allgar BSc CStat

Centre for Research in Primary Care, University of Leeds, Leeds UK

Submitted for publication 31 October 2002

Accepted for publication 17 July 2003

Correspondence:

Susan Procter,

Primary Healthcare Research,

Public Health and Primary Care Unit,

St Bartholomew's School of Nursing and

Midwifery,

City University,

Alexandra Building,

Philpot Street,

London E1 2EA,

UK.

E-mail:s.procter@city.ac.uk
PEARSON P., PROCTER S., WILCOCKSON J. \& ALLGAR V. (2004) Journal of Advanced Nursing 46(5), 1-12

The process of hospital discharge for medical patients: a model

Background. The 1990 NHS Community Care Act established a requirement for hospital discharge policies and procedures in the United Kingdom (UK) to be developed in collaboration with local government authorities in order to ensure supported discharge for those in need.

Aims. The aim of the study reported in this paper was to track decisions about hospital discharge in relation to outcomes for a sample of medical patients and their carers, identified as at risk of experiencing unsuccessful discharge processes.

Methods. Themed unstructured interviews were conducted in three different hospitals with 30 patients identified as at risk of unsuccessful discharge and their carers pre- and postdischarge. Hospital, community and social care staff involved in the care of the patient were also interviewed.

Findings. Patients and carers were constantly negotiating their social roles, seeking to juggle appropriate identities and limited resources to maintain their own and each others' dignity and quality of life. When the negotiation process was destabilized (for example, by exacerbation of chronic disease, withdrawal of some resource, or the experience of additional stressors - not necessarily health-related), then either or both parties sought a way out. In all the cases examined the result was admission to hospital - usually, but not always, mediated by community professionals.

Conclusions. The effective discharge of patients from hospital needs to move from a functional focus on symptom management to a negotiation of quality of life that seeks to promote health for all parties involved.

Keywords: hospital discharge, readmission, delayed discharge, quality of life, social role, nursing

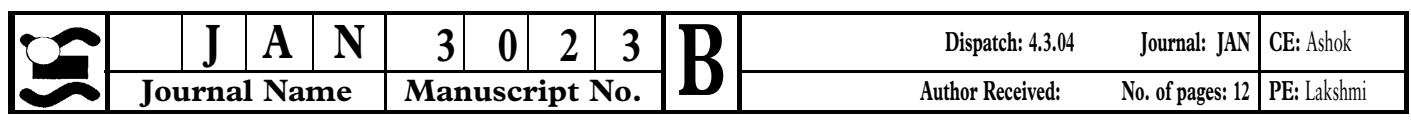




\section{Introduction}

More than eight million people are admitted to hospital in the United Kingdom (UK) every year (Department of Health

31996), and most are discharged successfully. However, some patients are at risk of difficult or problematic discharge (Rockwood 1990, Kalman et al. 1994, Escalante \&

4 Beardmore 1997, Lyons et al. 1997). This paper describes findings from a study that combined quantitative and qualitative methods to investigate the process of hospital discharge experienced by patients 'at risk' of unsuccessful discharge from medical wards in three hospitals in the north

5 of England (Pearson et al. 1999). The first phase of the study used quantitative methods to highlight factors that predict existing patterns of discharge and readmission for medical patients. The findings from the first phase are reported elsewhere (Allgar et al. 2002). This paper reports the qualitative findings on decision-making processes and outcomes related to discharge. A model is outlined which draws together the analysis of the qualitative data and indicates some key areas for change in considering patient discharge (Figure 1).

For the purposes of this research unsuccessful discharge was defined as unplanned readmission within 6 weeks of discharge, or delayed discharge. Delayed discharge was defined as an individual length of stay for a particular age group, consultant and condition which is greater than a standardized threshold for mean length of stay by the respective consultant and condition derived for the whole population (Audit Commission 1992).

\section{Defining problematic of unsuccessful discharge}

There is increasing international recognition of the need to 6 integrate health and social care services (Israel et al. 1998). The National Health Service and Community Care Act (1990) in the UK established a requirement for UK hospital discharge policies and procedures to be developed in collaboration with local government authorities, who are required to undertake needs-based assessment for community care prior to the discharge of patients assessed as needing additional support after discharge.

Qualitative research has identified health and social care professionals' awareness of the vulnerability of some patients following discharge and their concern about those patients (Macmillan 1994). However, pressure on hospital beds, poor liaison between hospital and community staff, lack of preparation for discharge, difficulties in managing at home and limited provision of health and social services in the postdischarge period have all been identified as factors leading to unsuccessful discharge (Tierney et al. 1993, Victor 7 et al. 1993, Neill \& Williams 1992, Jewell 1993). Discharge planning is thought to benefit hospitals by reducing length of stay and readmission rates. However, the benefit of the process for patients and families has not been established and the costs of additional hospital and community resources are rarely considered (Jackson 1994).

Policy and quantitative research on discharge has been dominated by organizational outcome indicators in which unsuccessful discharge is frequently defined as unplanned early readmission or delayed discharge (Rockwood 1990, 8,9Kalman et al. 1994, Weissman et al. 1994, Kalman \&

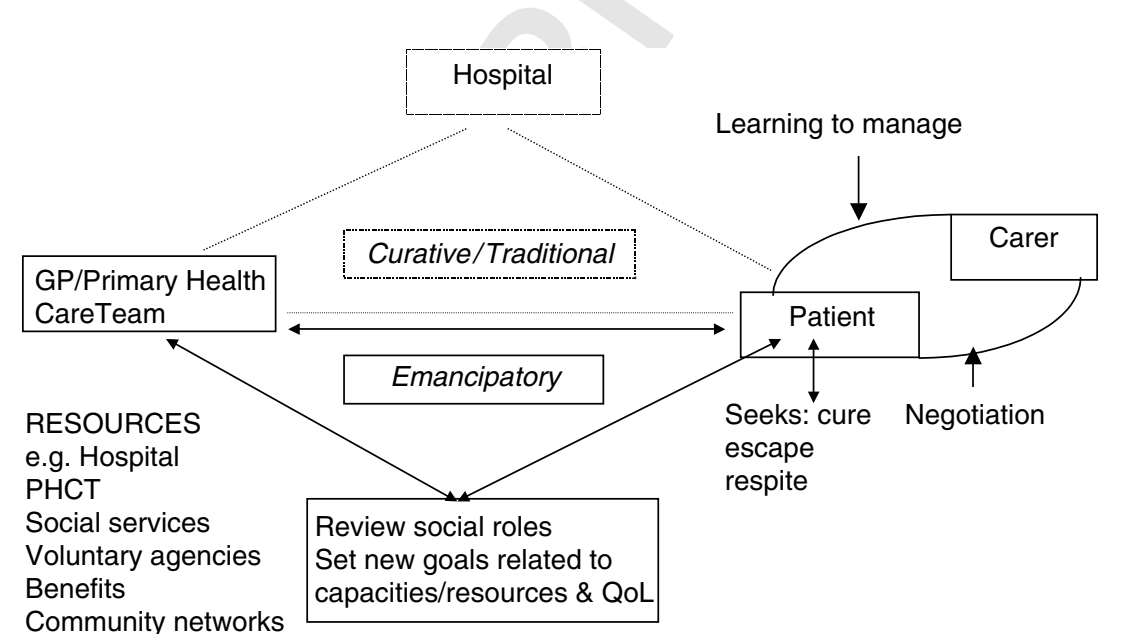

$\mathrm{GP}=$ General Practitioner

PHCT $=$ Primary Health Care Trust

QoL $=$ Quality of Life

Figure 1 A model depicting the current and proposed approaches to discharging medical patients from hospital. 
10,11 Johnston 1996, Monane et al. 1996, Escalante \& 12Beardmore 1997). The readmission periods used range from 1 week to 1 year (Jackson 1994). No consensus exists on defining appropriate length of stay or delayed discharge. Using organizational outcome indicators such as readmission and length of stay makes it difficult to disaggregate the measured outcomes from the supply of services (Clarke 1996). Only recently has the focus for research into effective discharge planning been on predicting patients at risk of unsuccessful discharge and developing patientorientated outcome indicators for measuring successful discharge.

\section{The study}

\section{Aim}

The aim of the study was to track decisions about hospital discharge in relation to outcomes for a sample of medical patients and their carers identified as at risk of experiencing unsuccessful discharge processes.

\section{Design}

The study took place in three stages. Stage one, the quantitative phase, used clinical data routinely collected by community nurses and data from hospital and community patient notes to develop an enhanced data set containing information on medical discharges from each site between April 1993 and March 1995. Logistic regression was used to develop site-specific equations designed to identify patients at risk of unsuccessful discharge (Allgar et al. 2002).

In stage two, reported here, a sample of 30 medical patients anticipated to be at risk of unsuccessful discharge, and their associated formal and informal carers, were followed through the discharge process.

In stage three of the study, people engaged in developing and implementing discharge policy in the three districts were interviewed, including strategic and operational managers in trusts and health authorities, general practitioners (GPs) and social services staff. An analysis of the findings looked at the way discharge planning was conceptualized, the problems presented by it and the solutions favoured.

\section{Method - phase two}

Stage two of the research was designed to obtain in-depth understanding of the process of discharge experienced by patients at risk of early unplanned readmission or extended length of stay, and to identify how that process influenced outcome. Patients' understandings of their own needs were compared with their carers' ideas of need, and with ideas about need derived from different members of the multiprofessional team involved in their care, both in hospital and following discharge into the community.

\section{Sample}

Data were collected in the three participating hospitals during 1997-1998. Hospital A is a regional centre for health care, meeting the local health needs of an urban population and regional health needs of both an urban and rural population. Hospital B is situated in a geographically large area with a widely dispersed, mainly rural population. Hospital $\mathrm{C}$ is an urban non-teaching hospital. These sites were selected because they were known to have divergent discharge arrangements.

The sampling strategy was based on the equations developed in the first phase of the study to identify people likely to experience unsuccessful discharge. This strategy was supplemented with purposive sampling to include people identified as likely to experience particular types of referral (for example, to occupational therapy and/or physiotherapy), and those who seemed more likely to be transferred to other units, such as a community hospital or rehabilitation unit. This process enabled us to recruit patients whom the staff identified as likely to have a difficult discharge. Originally it was intended to obtain two interviews from each patient, but completed sequences were only available for 21. Eight withdrew from the study after returning home, and one died.

The overall readmission rate for the three hospitals was 13 $17 \%$ (Allgar et al. 2002). Table 1 presents data on the 30 patients studied in stage two of the study, and demonstrates their general frailty and wide range of pathologies. The mean length of stay of the sample was 19.6 days, with a range from 3 to 93 days. Twenty-two were in hospital longer than the mean consultant episode for their unit, with 13 (almost half) exceeding the mean consultant episode by more than one SD. Others were re-admitted on one or more occasions during the data collection period. Eleven (36\%) were re-admitted within 6 weeks of discharge, and a further four were re-admitted with a related problem during the study period. Although recruited prospectively, the patients in stage two appear to provide a reasonable snapshot of problematic discharge for medical patients.

Table 2 gives the total number of staff interviews. Difficulties with access and the fact that not all patients received input from all of the multi-professional team explain the variability. 


\section{P. Pearson et al.}

Table 1 The patients studied

\begin{tabular}{|c|c|c|c|c|c|}
\hline Code & Sex & $\begin{array}{l}\text { Age } \\
\text { (years) }\end{array}$ & $\begin{array}{l}\text { Presenting } \\
\text { problem }\end{array}$ & $\begin{array}{l}\text { Length of } \\
\text { stay (days) }\end{array}$ & Readmission \\
\hline \multicolumn{6}{|c|}{ Study site A } \\
\hline 1 & $\mathrm{~F}$ & $70 \mathrm{~s}$ & Angiodysplasia & 8 & Y \\
\hline 2 & M & $70 \mathrm{~s}$ & Exacerbation of chronic obstructive pulmonary disease & 10 & Y \\
\hline 3 & M & $30 \mathrm{~s}$ & Chest pain & 3 & $\mathrm{~N}$ \\
\hline 4 & $\mathrm{~F}$ & $30 \mathrm{~s}$ & Deep vein thrombosis ?pulmonary embolus & 18 & $\mathrm{Y}$ \\
\hline 5 & $\mathrm{~F}$ & Late $70 \mathrm{~s}$ & Deep vein thrombosis (later diagnosis cellulitis) & 5 & $\mathrm{~N}$ \\
\hline 6 & $\mathrm{~F}$ & $70 \mathrm{~s}$ & Stroke & 15 & $\mathrm{~N}$ \\
\hline 7 & $\mathrm{~F}$ & $70 \mathrm{~s}$ & Heart failure & 6 & $\mathrm{~N}$ \\
\hline 8 & M & 70 & Painful legs, pressure sore, multiple problems & 21 & $\mathrm{Y}$ \\
\hline \multicolumn{6}{|c|}{ Study site B } \\
\hline 1 & M & 89 & Exacerbation of chronic obstructive pulmonary disease & 55 & 8 weeks \\
\hline 2 & $\mathrm{M}$ & 90 & Peptic ulcer & & \\
\hline 3 & $\mathrm{~F}$ & 77 & Myocardial infarction & 8 & $\mathrm{~N}$ \\
\hline 4 & $\mathrm{M}$ & 74 & Chest pain & 5 & $\mathrm{~N}$ \\
\hline 5 & $\mathrm{~F}$ & 73 & Collapse, multiple problems, blind & & \\
\hline 6 & $\mathrm{~F}$ & 77 & Chronic obstructive pulmonary disease, deep vein thrombosis & 19 & $\mathrm{~N}$ \\
\hline 7 & $\mathrm{~F}$ & 77 & Stroke & 47 & $\mathrm{~N}$ \\
\hline 8 & $\mathrm{M}$ & 50 & Status epilepticus & 65 & Y \\
\hline 9 & M & 73 & Chest pain & 9 & Y \\
\hline \multicolumn{6}{|c|}{ Study site C } \\
\hline 1 & $\mathrm{~F}$ & 71 & Stroke & 17 & Y \\
\hline 2 & M & 60 & Postural hypertension and bleed & 13 & $\mathrm{~N}$ \\
\hline 3 & $\mathrm{~F}$ & 89 & Heart failure & 22 & $\mathrm{~N}$ \\
\hline 4 & M & 63 & Angina & 4 & $\mathrm{~N}$ \\
\hline 5 & $\mathrm{~F}$ & 18 & Infective exacerbation of asthma & 9 & $7 \cdot 5$ Weeks \\
\hline 6 & $\mathrm{M}$ & 55 & Myocardial infarction & 12 & Y \\
\hline 7 & M & 70 & Unstable angina & 16 & $\mathrm{Y}$ \\
\hline 8 & $\mathrm{~F}$ & 72 & Unable to eat & 12 & Y \\
\hline 9 & $\mathrm{~F}$ & 73 & Collapsed at home, leg ulcers & 93 & $\mathrm{~N}$ \\
\hline 10 & $\mathrm{M}$ & 76 & Heart failure, not eating & 16 & $\mathrm{~N}$ \\
\hline 11 & $\mathrm{M}$ & 76 & Exacerbation of chronic obstructive pulmonary disease & 26 & Y \\
\hline 12 & $\mathrm{M}$ & 64 & Alcoholism & & $10 \cdot 5$ Weeks \\
\hline 13 & $\mathrm{~F}$ & 77 & Rheumatoid arthritis, depression, urinary tract infection & 55 & 13 Weeks \\
\hline
\end{tabular}

M, male; F, female; N, no; Y, yes

\section{Interviews}

A guided interview approach was used in which a series of topics were used as prompts by the interviewer (Miller \& Crabtree 1999). The topic guide was developed following pilot work. Prompts used with patients included questions about their illness, how it affected their life, help patient received, and how they might and did manage on discharge. Interviews with carers sought information on their assessment of patients' needs for care, the type and frequency of help that they gave to patients, how this affected their lives, and what they thought would help maintain patients' independence.

The majority of patient or carer interviews were tape recorded and transcribed. Accounts tended to be unfocused and not to present a coherent picture of events. In contrast, interviews with professional staff tended to be very brief (constrained by workload pressures) and more factual.

Interviews with staff outside the hospital setting were conducted by telephone and not tape recorded. Detailed notes were made of all interviews.

\section{Ethical considerations}

Ethical approval for the study was granted by all three Local Research Ethics Committees. An information sheet explaining the study was given to potential participants and written consent was obtained by the researcher collecting the data once they had agreed to participate. Patients were also asked to identify their main carer and to give consent for the researcher to approach this person. The named carer was provided with 
Table 2 Number of professional and formal carers interviewed

\begin{tabular}{lll}
\hline Interviews conducted with & Number interviewed & Patients referred to \\
\hline Hospital Doctors & 26 & 26 \\
Hospital Nurses & 26 & 26 \\
Physiotherapists & 18 & 18 \\
Occupational Therapists & 7 & 7 \\
Dieticians & 4 & 4 \\
General Practitioners & 25 & 18 in contact with patient since discharge \\
District Nurses & 9 & 8 in contact with patient since discharge \\
Social Workers & 4 & 4 \\
Day Care Officer & 1 & 1 \\
Home Help & 1 & 1
\end{tabular}

written information about the study and their written consent was also obtained. Permission was also obtained from the patient to approach their professional carers, who were then provided with written information about the study and their written consent was obtained. Consent was again sought from patients and carers at the postdischarge interview. Written assurances of anonymity and confidentiality were given to all participants. Tapes were deleted following transcription, and all transcripts were anonymized. Patients and carers were assured that care and treatment would not be affected by decisions taken in relation to the study.

\section{Data analysis}

The transcripts were entered into the NUD.IST software package and initially coded by one of the researchers. Each member of the wider research team worked through a sample of raw transcripts to establish the validity of the coding system being developed. Each transcript was seen by more than one member of the team. An iterative process evolved whereby the themes emerging from the analysis were brought to team meetings, along with the supporting evidence. The themes were discussed and interpreted at the meeting and interpretations checked for validity with the whole data set. The analytic process was thematic (Silverman 1993), we sought to ensure the inclusion of every case in the development of the final model (Figure 1).

\section{Findings}

Four distinct groups who shared similar experiences in relation to the discharge process were identified: patients, carers, hospital staff and community staff. The experiences of each group are presented here.

\section{Patients}

The analysis of patient interviews fell into three main themes: responses to illness, role performance and levels of available resource. The identity of each respondent quoted in the paper relates to the description given in Table 1. For example, C1 relates to patient 1 site $\mathrm{C}$.

\section{Responses to illness}

About a third of patients appeared to accept their illness as a part of life, something they had to manage:

I've managed very well up to now, but you haven't just to lie down and do nothing, have you? You've got to try your best to overcome things, haven't you? (Patient C1)

Most people in this group had experienced health problems for some time and relied heavily on family members to manage on a daily basis:

I don't need any extra help - I've got two daughters who do everything for me, and I don't need any other help. (Patient C2)

However, in four cases, people did not appear to have learnt how to deal with exacerbations of their illness. As a result they tended to panic, and often failed to cope:

He's chronically ill, he has a bad chest, he's always an emergency call and he is constantly short of breath. Mr X...tends to panic a bit...It's not really a condition [chronic obstructive pulmonary disease] to have if you're a bit panicky. He doesn't actually cope very well but, you know, he isn't a well man. (Patient's GP about Patient C11)

Other patients were either ambivalent about their illness or frankly did not accept it:

Doctor says it would be better now when she's well to have it [oesophageal dilatation] done and back on solid foods. He says she'll put her weight back straight on - but it's a waste of time, a waste of time. (Daughter C3)

Let me live in peace. [Refusing treatment, creating demand on daughter for care] (Patient C3)

Seven patients felt that they were lonely, and 15 said that they were isolated. For some the main issue was the 
health problem itself. Without that, they felt, they would cope:

I'm worried if I want to walk up to the club for a pint. I'm frightened to walk up to the club in case something happens halfway there. You see, it's happened three times in three weeks and for no reason - just lying in bed or sitting in the chair. That's why I wish they'd sorted it out there and then. (Patient C6)

\section{Maintaining identity and role performance}

For many patients the opportunity to sustain their previous values and identity while maintaining an appropriate social role was an important component of their ability to manage their health problem(s) successfully. The loss of social role was mourned:

Did you used to cook? (Interviewer)

Yes. (Patient B2)

He makes lovely Yorkshire puddings and gravy and makes a lovely dinner. (Daughter B2)

Not now. (Patient B2)

There's no way he could cook for himself now. He can open a tin of soup and boil an egg. (Daughter B2)

For about half of the patients there was evidence of some sort of reciprocity with another person, so that they were more than just a passive recipient of help:

Whilst I'm of no help to J, at least I'm company to her. (Patient A2)

Me son's bairns (children) go to a school in (local town), so when the school's finished they come to my flat and then he comes and picks them up, when his work's finished. They sort of keep us going. (Patient A1)

Maintaining personal values and past identity meant that some people took on the role of 'martyr', for example, refusing to adopt practical solutions to problems or refusing to 'give in' to the illness:

I think she thinks people of her sort of standard of living don't use taxis. (Daughter A7)

Now I've refused to take the pain killers. The doctor sent them but I wouldn't take them. I told the nurse, I says, 'I don't take pain killers.' I only took them in hospital to please them... (Patient A6)

Loss of identity, or fear of its loss, was an issue for 14 patients, and 10 commented that their illness prevented them from fulfilling previous roles. This was seen as particularly distressing by those who had been active contributors to family life. Changes such as moving to smaller accommodation or retiring were reluctantly accepted, symbolizing as they did a loss of status and control over life. Loss of self-esteem was most poignantly illustrated by the respondent who said that he did not think he had anything of importance to contribute to a research study.

\section{Levels of resource available}

There was considerable evidence from patient interviews that the way in which the illness or problem was managed at home was dependent upon the presence or absence of a variety of resources. For some, resources required to cope with illness were temporarily de-stabilized by carers' needs to address additional stressors elsewhere. One group of patients described experiencing a complex range of problems which generated 'extreme personal suffering' in addition to the illness that had apparently led to their admission. These problems included the suicide of a close family member, living with intense loneliness, collapse of a business and repercussions of a work-related injury on family life. Coping with these issues appeared to have consumed these people's capacity to move forward.

\section{Carers}

Carers perceived themselves as forming a 'barrier' in assessing patients' needs: of they were 'there', then they could cope. For example, one carer said that although she had a job and a young family, hospital staff increasingly assumed that she would take on support for her mother when she was discharged. Another described a feeling of being 'taken for granted' in her attempts to initiate a move into sheltered housing for her parent.

Carers also described the process of juggling their own needs, their family's needs and those of the patient. There was constant pressure to prioritise, with carers seeking to find a balance between different demands and drawing on what resources they could find. They identified a great deal of anxiety in caring, which was made worse by lack of information and by the perceived contradictory behaviour of professionals.

Several carers felt unsupported in their role, increasing their anxiety, and some experienced financial constraints adding to anxiety. They also highlighted the inadequacy of the environment in which patients were expected to recuperate after hospitalization - a setting which they saw as purposeful, compared with the isolation of the environment to which they were discharged. Carers' perspectives on their involvement in the discharge process are reported elsewhere (Procter et al. 2001). 


\section{Hospital staff}

Hospital staff were interviewed for all except one patient, who withdrew consent to further interviews after discharge. However, rotation changes meant that detailed information was not available for three patients. Medical staff described most cases as 'straightforward'. Those who were not fell into two groups - those where diagnosis had been difficult and others where complications or concomitant illness occurred. Treatment was changed during the hospital stay for a majority of patients. Doctors made 37 referrals in relation to this group of patients and intended to follow-up all but three patients after discharge, most in outpatient clinics. Concerns were expressed in relation to 11 patients, where discharge was thought likely to be problematic. Seven of these patients were re-admitted.

Despite efforts to interview the member of the nursing staff who knew the patient best, the degree of familiarity of nurses with patients was variable. Whilst in 19 cases nurses felt they knew the patient well, two said they hardly knew them. One nurse said that she had discharged a patient because she was the only nurse available when other staff were on their tea break.

Nurses highlighted five types of decision in relation to discharge. In 'straightforward' cases, a discharge date could be predicted in advance and was usually adhered to. In a second group, the decision about discharge was made on a ward round and was generally completed within 24 hours. A third group of decisions depended on a 'satisfactory' result - for example, from an investigation or an assessment. For two patients, it appeared to have been the nurse who decided they were fit to be discharged, and for five discharge was dependent on availability of a place elsewhere. Nurses made a total of 35 referrals for 26 patients, with seven patients requiring none. Preparation for discharge was mainly described in terms of ordering drugs and arranging transport. Letters to GPs were mentioned by 10 nurses and information to relatives by seven. Four nurses mentioned some consideration of the patient's home circumstances. Asked how they thought the patient would manage at home, nurses' comments ranged from a relatively cautious:

He said he would be OK when he got home. (Nurse about Patient C2) to a more confident:

She'll manage really well. (Nurse about Patient B7)

Almost half said that they thought that the patient would manage 'all right' or 'quite well' at home. Although in nine cases nurses picked out information about the patient's situation which indicated a high level of understanding, some indicated their problems in achieving this:
Because we are short-staffed we can only have a basic knowledge about each patient, and I suppose this kind of defeats the object of primary nursing.

Data were collected from occupational therapists (OTs) for six patients (it was unclear whether one other person had actually been referred) and from physiotherapists for 17 (no information was available for one who had been seen by a student). Occupational Therapists at all sites identified problems of lack of resources. At one site shortages of OT staff were said to result in high levels of transfer to another unit for assessment, and there was some evidence of this. At another site, OTs could only provide 'discharge services' rather than additional rehabilitation.

The main problems addressed by physiotherapists were mobility problems (13) and chest problems (4). The main contribution of the physiotherapists in relation to the discharge decision was described by them as 'the stairs test'; six patients had this and all 'passed'. One patient received 25 physiotherapy sessions in relation to poor mobility, took part in an exercise programme and was given a walking frame, but the physiotherapist did not attend the home visit prior to discharge. No concerns about discharge were expressed by the physiotherapist, as this patient had 'been rehoused in a bungalow'. However, at the second interview with this patient she was unable to use her walking frame due to obstruction by furniture. No follow-up was arranged by physiotherapists for any patients.

\section{Community staff}

General practitioner data were collected for 25 patients, of whom all but seven had been in contact with their GP after discharge. GPs described 'picking up the pieces' following discharge. In two cases the patient did not appear to be fit for discharge when sent home. In another, several home visits were required to deal with continuing diarrhoea following antibiotic treatment. In another, three visits were made in relation to the patient's bad chest and pain associated with a pressure ulcer. GPs also sought clarification from hospital consultants about the date of follow-up investigations and medication provided. Communication was often poor, as the following extract indicates:

The hospital hadn't told him [GP] the diagnosis of the patient, GP didn't know whether the patient had a benign tumour or a malignancy. The relative had been told to ask the GP to fill out a 
form...GP said he received only a short discharge letter, he didn't know which hospital it came from, he didn't know what ward number and he said that he had asked for something more detailed and that he had rung up and weeks gone by and he's received nothing. The patient's been out of hospital for six weeks to two months and with so little information, yet he's expected to fill out this form. (Transcript notes GP about Patient C10)

In three cases, GPs expressed doubt about the causes of patients' readmissions. In one case the GP felt that there were psychological elements which led to readmission. In another, the GP said that care tended to break down because the patient was very demanding, but that hospitalization did not have much to contribute to their care. In the third situation, the GP felt that the patient and his carer did not 'do very well' in their present situation, but that the patient might be managed in a different type of environment.

Finally, the GP data highlighted the issue of whose responsibility patients are at any given time. For example, in one case the GP felt that the management of a patient was 'all to pot' (chaotic) but felt unable to initiate the tests he felt were needed. In another case, the GP highlighted the need for a clear line of responsibility for a 'young' chronically ill patient, but was unsure about his own role.

District nursing data were available for eight patients, and two key themes emerged. The first again highlighted the undiscovered problems with which patients were discharged. The second concerned the decision-making process of hospital staff who did or did not refer patients to the district nursing service. One patient who had been receiving a monthly visit from a district nurse prior to admission to hospital was discharged with a hospital-acquired, but undetected, pressure ulcer that was discovered by the care worker at her next routine visit. This then needed twice weekly visits by a district nurse, and a number of GP visits. Another patient was referred to the district nursing service because she had difficulty getting into the bath. District nurses felt that some hospital staff might not recognize the full extent of the district nursing role, since they tended to refer mainly patients who required practical tasks to be performed, omitting others where advice and support were needed. They felt that the hospital referrals were for 'nursey jobs'.

\section{Discussion}

Detailed examination of the themes and case study data has enabled development of a model describing the patterns of care which contribute to unsuccessful patient discharge, and highlighting some of the possible ways forward.

\section{The players}

There are four sets of players in the process of getting a patient home from hospital: hospital-based professionals, community-based professionals, and patients and carers. The evidence suggests that in day-to-day life, patients and carers negotiate their social roles, seeking to juggle socially-appropriate identities and limited resources to maintain their own and each others' dignity and to secure an acceptable quality of life. Each undertakes this negotiation from a position defined by their knowledge and experience - of the illness, and available resources. Where factors intervene to destabilize the negotiation process, whether through exacerbation of chronic disease, withdrawal of some resource, or additional stressors (not necessarily health-related), then either or both of these players seeks a way out. This might be by the patient seeking relief of symptoms, or the family wanting respite care. In all the cases examined, the result was admission to hospital - usually, but not always, mediated by community professionals.

In hospital, there is another set of relationships for patients. There is evidence of multiple players, each with a part of the picture, set against a context which is almost constantly changing. The other key relationship is between the professionals who work primarily in the hospital, and those who work outside. Hospital consultants and GPs noted the difficulties they experienced in identifying who was responsible for taking action in relation to any particular patient, and the resultant postponement of decision-making. District nurses highlighted the failure of hospital staff to perceive the breadth of their potential role.

\section{The script}

There are two, linked stories within the 'script': the achievement of tertiary prevention (a process of rehabilitation and recovery of optimal function, avoiding, as far as possible, future risk) and the search for quality of life (negotiating more or less realistic goals in relation to current capacities and available resources). Both of these are widely discussed in health care literature, but are not generally seen as central to the discharge debate.

\section{The stage}

The structure within which discharge is played out could broadly be equated with a stage. Initial decisions about entry to hospital were taken in the community, often initiated by the patient-carer dyad (Procter et al. 2001). There was 


\section{What is already known about this topic}

- Health and social care professionals' are aware of the vulnerability of some patients following discharge and are concerned about those patients.

- Pressure on hospital beds, poor liaison between hospital and community staff, lack of preparation for discharge, difficulties in managing at home and limited provision of health and social services in the postdischarge period are all factors leading to unsuccessful discharge.

- Policy documents recommend improving discharge planning processes in order to reduce length of hospital stay and readmission rates and improve the patient experience postdischarge.

\section{What this paper adds}

- Admission to hospital for patients at risk of unsuccessful discharge results from destabilization of the complex negotiation process used to maintain these patients at home.

- Intervening factors such as an exacerbation of chronic disease, withdrawal of some resource, or the experience of additional stressors - not necessarily health-related can cause the patient or main carer or both to seek a way out, and this may this result in hospital admission.

- A model for planning the admission and discharge of these patients which focuses on negotiation of quality of life that seeks to promote health for all parties, rather than the current functional focus on symptom management.

evidence that the original admission to hospital, and any readmission, was often focused on a very general goal of obtaining relief and re-establishing balance. Community professionals expressed uncertainty about whether hospital was appropriate for some people - but it was seen as the only option. Once the patient was in hospital, however, the scripts seemed to diverge, as described above. The achievement of tertiary prevention and the search for 'quality of life' favoured by patients and, for themselves, by carers gave way to the professionals' goal of achieving a minimum functional threshold for health, exemplified by the physiotherapists' 'stairs test'.

\section{Where now?}

Figure 1 is a diagrammatic representation of the model. The top section outlines the process through which most patients went. The lower section (developed with reference to Antonovsky's salutogenic model, Antonovsky 1996) represents the process of assessment and re-setting of goals which, we would suggest, could replace or reduce the repeating cycle of admission and discharge, and might also impact on length of stay. This process could occur in hospital or in the community: either way, it needs to be carried forward by a worker with an awareness of the patient and carer in their environment, and a focus on quality of life as a central measure of 'health'.

The increasing pressure to make best use of expensive hospital technology has led to decreasing length of hospital stays and throughput (Abel-Smith 1994). These have to be accommodated alongside an aging population increasingly characterized by chronic and enduring illness profiles, which lead to considerable vulnerability (Murray \& Lopez 1996). In the context of cost-effective use of medical technology, the emphasis on physiological and physical functioning as indicators for discharge from hospital, as identified in this study, appears entirely appropriate. However, the qualitative data from patients and carers highlight the psycho-social consequences of living with chronic and degenerating illness. The importance of maintaining quality of life for both patients and carers, and of sustaining the social role and integrity of patients, appear to be crucial to managing the disease trajectory effectively. Failure to address these issues rebounds on hospital and community services in unpredictable ways, creating a series of crises to which the service can only provide ad boc responses.

These findings are not new. Jewell (1993) highlighted the subordination of patients, carers and community staff to hospital staff in the discharge process and the almost total absence of GP input. Tierney et al. (1993) noted the concern expressed by hospital staff about the vulnerability of older patients following discharge from hospital; however they found little evidence of discharge arrangements or continuing care being systematically planned on the basis of individually-assessed circumstances and needs. Dansky et al. (1996) found skilled community nursing following discharge improved outcomes for very old patients.

In response to these problems, the Department of Health has highlighted three areas as central to effective patient discharge (Henwood 1994): a multi-disciplinary approach to discharge planning; the need to start planning for discharge as soon after admission as possible; and the need to involve patients and carers actively at the centre of the discharge process. 


\section{Conclusion}

The findings from this study reinforce the need for such active involvement of patients and carers. However, the model proposed in this study indicates the impact on care experiences produced by the traditional focus on curative medicine which dominates hospital-orientated health care systems. Shifting to an emancipatory focus requires a realistic appraisal of the strengths and limitations of these care systems in addressing the complex needs of patients. A failure to address these issues means the continuation of current approaches to service provision, a limited and functional approach to discharge planning, and increasing difficulties in improving the cost-effectiveness of hospital services. Faced with the vulnerability of patients and carers, and in the absence of alternative services orientated to maintaining quality of life in the face of enduring or chronic illness, it is likely that health care professionals will continue to use hospitals as sanctuaries of care rather than places of technological excellence. This leads to pressure on services such that neither excellence in technological medicine nor quality of care across the primary-secondary interface can be effectively achieved.

\section{Acknowledgements}

We would like to thank all the patients, carers and professionals who contributed to this research. We would also like to thank the NHSE Primary/Secondary Interface Programme for funding the work.

\section{References}

Abel-Smith B. (1994) Introduction to Health Policy, Planning and Financing. Longman, London.

Allgar V., Procter S., Pearson P., Lock C., Taylor G., Wilcockson J., Foster D. \& Spendiff A. (2002) Readmissions - Can they be predicted on admission? Health Informatics Journal 8(3), 138-146.

Antonovsky A. (1996) The salutogenic model as a theory to guide health promotion. Health Promotion International 11(1), 11-18.

Audit Commission (1992) Lying in Wait: The Use of Medical Beds in Acute Hospitals. HMSO, London.

Clarke A. (1996) Why are we trying to reduce length of stay? Evaluation of the costs and benefits of reducing time in hospital must start from the objectives that govern the change. Quality in Health Care 5, 172-179.

Dansky K.H., Dellasega C., Shellenbarger T. \& Russo P.C. (1996) After hospitalization: home, health care for elderly persons. Clinical Nursing Research 5(2), 185-198.

Escalante A. \& Beardmore T.D. (1997) Predicting length of stay after hip or knee replacement for rheumatoid arthritis [see comments]. Journal of Rheumatology 24(1), 146-152.

Henwood M. (ed.) (1994) Hospital Discharge Workbook: A Manual 14 on Hospital Discharge Practice. Department of Health.
Israel B.A., Schulz A.J., Parker E.A. \& Becker A. (1998) Review of community based research: assessing partnership approaches to improve public health. Annual Review of Public Health 19, 173202.

Jackson M.F. (1994) Discharge planning: issues and challenges for gerontological nursing. A critique of the literature. Journal of Advanced Nursing 19, 492-502.

Jewell S.E. (1993) Discovery of the discharge process: a study of patient discharge from a care unit for elderly people. Journal of Advanced Nursing 18(8), 1288-1296.

Kalman P.G. \& Johnston K.W. (1996) Sociologic factors are major determinants of prolonged hospital stay after abdominal aneurysm repair. Surgery 119(6), 690-693.

Kalman P.G., Johnston K.W., Walker P.M. \& Lindsay T.F. (1994) Preoperative factors that predict hospital length of stay after distal arterial bypass. Journal of Vascular Surgery 20, 70-75.

Lyons J.S., O’Mahoney M.T., Miller S.I., Neme J., Kabat J. \& Miller F. (1997) Predicting readmission to the psychiatric hospital in a managed care environment: implications for quality indicators. American Journal of Psychiatry 154(3), 337-340.

Macmillan M.S. (1994) Hospital staff's perceptions of risk associated with the discharge of elderly people from acute hospital care. Journal of Advanced Nursing 19, 249-256.

Miller W.L. \& Crabtree B.J. (1999) Clinical research a multimethod typology and qualitative roadmap. In Doing Qualitative Research (Crabtree B.J. \& Miller W.L., eds) Sage, London, pp. 3-30.

Monane M., Kanter D.S., Glynn R.J. \& Avorn J. (1996) Variability in length of hospitalization for stroke - the role of managed care in an elderly population. Archives of Neurology 53(9), 875-880.

Murray C.J.L. \& Lopez A.D. (eds) (1996) The Global Burden of Disease: A Comprehensive Assessment of Mortality and Disability From Diseases, Injuries, and Risk Factors in 1990 and Projected to 2020. Harvard University Press, Boston, MA.

Neill J. \& Williams J. (1992) Leaving Hospital: Elderly People and their Discharge to Community Care. Institute for Social Research Work Research Unit, HMSO, London.

Pearson P., Procter S., Allgar V., Wilcockson J., Lock C., Spendiff A., Davison N., Taylor G. \& Forster D. (1999) Discharging Patients Effectively Planning for Best Care. Report prepared for the NHSE

Procter S., Wilcockson J., Pearson P. \& Allgar V. (2001) Going home from hospital: the carer c/patient dyad. Journal of Advanced Nursing 35(2), 206-217.

Rockwood K. (1990) Delays in discharge of elderly patients. Journal of Clinical Epidemiology 43, 971-975.

Silverman D. (1993) Interpreting Qualitative Data: Methods for Analysing Talk, Text and Interaction. Sage, London.

The National Health Service and Community Care Act (1990) The National Health Service and Community Care Act 1990 (c. 19). The Stationary Office Ltd, London.

Tierney A.J., Closs S.J., Hunter H.C. \& Macmillan M.S. (1993) Experiences of elderly patients concerning discharge from hospital. Journal of Clinical Nursing 2, 179-185.

Weissman J.S., Stern R.S. \& Epstein A.M. (1994) The impact of patient socioeconomic status and other social factors on readmission: a prospective study in four Massachusetts hospitals. Inquiry 31, 163-172. 


\section{Author Query Form}

\section{Journal: $\quad$ JAN}

Article: $\quad 3023$

Dear Author,

During the copy-editing of your paper, the following queries arose. Please respond to these by marking up your proofs with the necessary changes/additions. Please write your answers on the query sheet if there is insufficient space on the page proofs. Please write clearly and follow the conventions shown on the attached corrections sheet. If returning the proof by fax do not write too close to the paper's edge. Please remember that illegible mark-ups may delay publication.

Many thanks for your assistance.

\begin{tabular}{|c|c|c|}
\hline $\begin{array}{l}\text { Query } \\
\text { reference }\end{array}$ & Query & Remarks \\
\hline 1 & Au: Please approve suggested short title & \\
\hline 2 & Au: Please provide authors' designation for all authors & \\
\hline 3 & $\begin{array}{l}\text { Au: Department of Health } 1996 \text { has not been included in the list, } \\
\text { please supply publication details }\end{array}$ & \\
\hline 4 & $\begin{array}{l}\text { Au: Lyons } 1997 \text { has been changed to Lyons et al. } 1997 \text { so that this } \\
\text { citation matches the list }\end{array}$ & \\
\hline 5 & $\begin{array}{l}\text { Au: Pearson et al. } 1997 \text { has been changed to Pearson et al. } 1999 \text { so } \\
\text { that this citation matches the list }\end{array}$ & \\
\hline 6 & $\begin{array}{l}\text { Au: Israel } 1998 \text { has been changed to Israel et al. } 1998 \text { so that this } \\
\text { citation matches the list }\end{array}$ & \\
\hline 7 & $\begin{array}{l}\text { Au: Victor et al. } 1993 \text { has not been included in the list, please supply } \\
\text { publication details }\end{array}$ & \\
\hline 8 & $\begin{array}{l}\text { Au: Kalman } 1994 \text { has been changed to Kalman et al. } 1994 \text { so that this } \\
\text { citation matches the list }\end{array}$ & \\
\hline 9 & $\begin{array}{l}\text { Au: Weissman } 1994 \text { has been changed to Weissman et al. } 1994 \text { so that } \\
\text { this citation matches the list }\end{array}$ & \\
\hline 10 & $\begin{array}{l}\text { Au: Kalman, } 1996 \text { has been changed to Kalman \& Johnston } 1996 \text { so } \\
\text { that this citation matches the list }\end{array}$ & \\
\hline 11 & $\begin{array}{l}\text { Au: Monane } 1996 \text { has been changed to Monane et al. } 1996 \text { so that } \\
\text { this citation matches the list }\end{array}$ & \\
\hline 12 & $\begin{array}{l}\text { Au: Escalante } 1997 \text { has been changed to Escalante \& Beardmore } 1997 \\
\text { so that this citation matches the list }\end{array}$ & \\
\hline 13 & $\begin{array}{l}\text { Au: Allgar } 2002 \text { has been changed to Allgar et al. } 2002 \text { so that this } \\
\text { citation matches the list }\end{array}$ & \\
\hline 14 & Au: Please provide place of publication & \\
\hline
\end{tabular}


15

Au: Please provide place of publication 


\section{Please correct and return this set}

Please use the proof correction marks shown below for all alterations and corrections. If you wish to return your proof by fax you should ensure that all amendments are written clearly in dark ink and are made well within the page margins.

\begin{tabular}{|c|c|c|}
\hline Instruction to printer & Textual mark & Marginal mark \\
\hline Leave unchanged & ... under matter to remain & Stet \\
\hline $\begin{array}{l}\text { Insert in text the matter } \\
\text { indicated in the margin }\end{array}$ & $h$ & New matter followed by \\
\hline Delete & $\mapsto$ through matter to be deleted & $\delta$ \\
\hline Delete and close up & E through matter to be deleted & की \\
\hline $\begin{array}{l}\text { Substitute character or } \\
\text { substitute part of one or } \\
\text { more word(s) }\end{array}$ & $\begin{array}{l}/ \text { through letter or } \mapsto \text { through } \\
\text { word }\end{array}$ & New letter or new word \\
\hline Change to italics & - under matter to be changed & لس \\
\hline Change to capitals & $\equiv$ under matter to be changed & $\equiv$ \\
\hline Change to small capitals & $=$ under matter to be changed & $=$ \\
\hline Change to bold type & m under matter to be changed & $m$ \\
\hline Change to bold italic & $\bar{\approx}$ under matter to be changed & 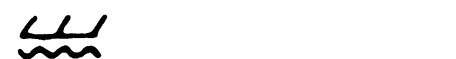 \\
\hline Change to lower case & Encircle matter to be changed & $\#$ \\
\hline Change italic to upright type & (As above) & \\
\hline Insert 'superior' character & $\begin{array}{l}/ \text { through character or } \wedge \text { where } \\
\text { required }\end{array}$ & $\begin{array}{l}\text { y under character } \\
\text { e.g. } 2 y\end{array}$ \\
\hline Insert 'inferior' character & (As above) & $\boldsymbol{L}$ over character e.g. $\mathbf{2}$ \\
\hline Insert full $\mathrm{s}$ & (As abc & ○ \\
\hline Insert comma & (As above) & , \\
\hline Insert single quotation marks & (As abo & $y$ and/or $y$ \\
\hline $\begin{array}{l}\text { Insert double quotation } \\
\text { marks }\end{array}$ & (As above) & $\ddot{y}$ and/or $y$ \\
\hline Insert hyphen & (As : & (4y) \\
\hline Start new paragraph & $\sqrt{-10}$ & $\overline{5}$ \\
\hline No new paragraph & 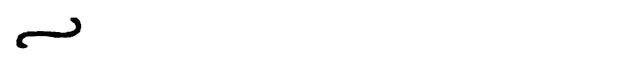 & 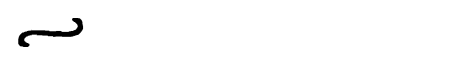 \\
\hline Transpose & حـ & 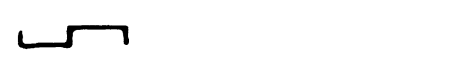 \\
\hline Close up & linking : & $=$ \\
\hline Insert space between letters & $\boldsymbol{h}$ between letters af & $\#$ \\
\hline Insert space between words & $\boldsymbol{h}$ between words affected & $\#$ \\
\hline Reduce space between letters & $\uparrow$ between letters affected & $T$ \\
\hline Reduce space between words & $\tau$ between words affected & \\
\hline
\end{tabular}

